\title{
Circulating tumor cells in breast cancer
}

\author{
Geetha Pukazhendhi' ${ }^{1}$, Stefan Glück ${ }^{1,2 *}$ \\ ${ }^{1}$ Departments of Medicine, Hematology Oncology Division, Miller School of Medicine, ${ }^{2}$ Sylvester Comprehensive Cancer Center, University of Miami, Miami, FL, USA \\ E-mail: s.gluck@med.miami.edu \\ *Corresponding author
}

Published: 30 June, 2014

Journal of Carcinogenesis 2014, I3:8

Received: 23 April, 2014

This article is available from: http://www.carcinogenesis.com/content//3/1/8

Accepted: 05 June, 2014

(c) 2014 Pukazhendhi

\begin{abstract}
Circulating tumor cell (CTC) measurement in peripheral blood of patients with breast cancer offers prognostic information. In this review, we will try to identify evidence that could be used for prognosis, predictive power to draw this tool to clinical utility. We reviewed 81 manuscripts, and categorized those in discovery datasets, prognostic factors in metastatic breast cancer, identification of clinical utility in early breast cancer and in novel approaches. With each patient responding differently to chemotherapy, more efficient markers would improve clinical outcome. Current CTC diagnostic techniques use epithelial markers predominantly; however, the most appropriate method is the measurement of circulating DNA. It has been hypothesized that micrometastasis occurs early in the development of tumors. That implies the presence of CTCs in nonmetastatic setting. The origin of stimulus for malignant transformation is yet unknown. The role of microenvironment as a stimulus is also being investigated. It has been shown that CTCs vary in numbers with chemotherapy. The markers, which are followed-up in the primary tumors, are also being studied on the CTCs. There is discordance of the human epidermal growth factor receptor-2 status between the primary tumor and CTCs. This review summarizes our current knowledge about the CTCs. With genetic profiling and molecular characterization of CTCs, it is possible to overcome the diagnostic difficulties. Evidence for clinical utility of CTC as prognostic and predictive marker is increasing. Appropriate patient stratification according to CTC determination among other tests, would make personalized cancer therapy more feasible.
\end{abstract}

Keywords: Cellsearch, circulating tumor cells, epithelial cell adhesion molecule, metastatic breast cancer, molecular profiling of circulating tumor cells

\section{INTRODUCTION}

Breast cancer is the most common malignant tumor in women. About $12.8 \%$ of women born today have a lifetime risk of being diagnosed with it. Based on the US National Cancer Institute Surveillance, Epidemiology, and End

\begin{tabular}{|l|l|}
\hline \multicolumn{2}{|c|}{ Access this article online } \\
\hline Quick Response Code: & Website: \\
\hline & www.carcinogenesis.com \\
\cline { 2 - 2 } & \\
\hline
\end{tabular}

Results database, the age adjusted incidence rate of breast cancer was 123.8 cases/100,000 women/year. ${ }^{[1]}$ The highest incidence (25.2\%) was between 55 and 64 years. Despite advances in detection and treatment strategies, most cancer-related deaths are due to metastatic growth. The 5 years relative survival for a metastasized cancer is $24.3 \%$. The period 1990-2007 saw a decline in death rates for breast cancer women both above and below 50 years $(2.0 \%$ and $3.2 \% / y e a r$, respectively). Surgery, radiation, endocrine therapy, trastuzumab, cytotoxic therapy, bisphosphonates, and other biological agents have contributed to this.

Adjuvant therapy decreases the probability of recurrences and developing metastatic breast cancer (MBC), but not complete 
prevention of these events. The seeding of tumor cells to distant sites occurs in parallel, independent, niche related adaptation tactics. ${ }^{[2]}$ Hence, treatment strategies targeting primary tumor profiling alone, may not be sufficient for a beneficial outcome. Metastases originate from a selected subpopulation of cells residing in a heterogeneous primary tumor. Most likely, this is a multifactorial step and depends on the interaction of tumor cells and the microenvironment.

Circulating tumor cells (CTCs) are isolated epithelial cells possessing the same or similar tumor characteristics as the primary cancer; these cells have been identified in the peripheral blood of solid tumor cancers, including breast cancer. Detection of these rare cells on a background of numerous hematopoietic cells poses a great challenge.

Cellsearch $^{\circledR}$ (Veridex, Warren, NJ, USA), a commercially available test, identifies cytokeratin (CK) (8, 18, and 19) positive, CD45 negative and nucleated cells as CTCs. ${ }^{[3]}$ Hence, analysis of targets identified on the primary tumor is now directed on the CTCs.

\section{METASTATIC PATHWAY}

The presence of tumor cells shed from the primary tumor could potentially predict the development of metastasis. It is likely that only a unique subpopulation of tumor cells possess the property to metastasize, e.g. cells that have the clonogenic potential and stem cell properties, a vast majority of other cells with "tumor cell" phenotype might not survive in the circulation. ${ }^{[4]}$ To initiate the cascade, the tumor cells (growth and proliferation) must penetrate the basement membrane (local invasion) and surrounding tissue to enter into circulation (intravasation). Downregulation of epithelial cadherin and upregulation of neural cadherin breaks cell to cell adhesion (mesenchymal phenotype). Degradation of extracellular matrix (ECM) is mediated by matrix metalloproteinases and urokinase plasminogen activator system. Epithelial mesenchymal transition (EMT) has been suggested to induce these changes (self sufficiency of growth signals) (survival in circulation). ${ }^{[5]}$ EMT related markers were found to be upregulated on CTCs and disseminated tumor cells (DTCs). Studies show the existence of a continuum in the development of CTC phenotypes ranging from epithelial to mesenchymal differentiation. EMT in CTCs, was analyzed in a study by Yu et al. ${ }^{[6]}$ They found that CTCs in lobular type cancers were predominantly epithelial while those from triple negative and human epidermal growth factor receptor-2 (HER2) positive cancers were predominantly mesenchymal. Furthermore, there was a decline in mesenchymal CTCs in patients who show response to treatment. Role of transforming growth factor (TGF) beta in
EMT has also been proposed. ${ }^{[7]}$ EMT-related markers showed worse prognosis more accurately, than epithelial markers. ${ }^{[8]}$ By including EMT markers, it is believed that most aggressive CTC phenotype can be identified. These cells show a potential to extravasation and adaptation to the microenvironment. ${ }^{[9]}$

Cancer cells in primary tumors are surrounded by complex microenvironment comprising of endothelial cells, stromal fibroblasts, and a variety of bone marrow derived cells, which include macrophages, neutrophils, and mesenchymal stem cells. ${ }^{[10]}$ This microenvironment plays a critical role in metastasis. The proteases required for degradation of ECM and the cell surface proteins, are supplied by cancer cells, tumor associated macrophages or both. The tumor associated macrophage increases invasiveness through epidermal growth factors. ${ }^{[9]}$ On entering the systemic circulation, CTCs are exposed to a hostile environment. Platelets form aggregates with tumor cells and protect them from natural killer cell mediated lysis. ${ }^{[10,11]}$ Thus, high platelet count is associated with decreased survival. Conversely treatment with anticoagulants has been shown to decrease metastasis.

Certain tumors metastasize to specific organs. This tropism is mediated by chemokines like stromal cell-derived factor-1 and CCL21, which are expressed at sites of metastasis. ${ }^{[10]}$ The corresponding receptor CXCR4 is overexpressed in the tumor cells. The niche (metastatic site) has to be primed for incoming tumor cells. Some studies say hematopoietic progenitor cells form the niche. On encountering the local microenvironment, DTCs revert back to an epithelial phenotype to allow adhesion and proliferation. Thus the secondary metastasis usually resembles the primary tumor phenotype. This reversal of EMT goes by mesenchymal epithelial transition (limitless replicative potential, tissue invasion and metastasis). ${ }^{[12]}$ Finally, the newly formed micro-metastases in distant tissues exhibit a potential to neovascularization (angiogenesis) to create a new environment for survival in the host tissues. In another study, presence of tumor clumps in the peritumoral vascular spaces was found to have prognostic significance in addition to tumor size and axillary nodal status. ${ }^{[13]}$

The relapse rate of estrogen receptor (ER) positive breast cancer, 7 or more years after tumor removal is about $1 \% /$ year for 20 years without further adjuvant therapy and can be decreased by anti-estrogen treatment by about $50-60 \% .^{[14]}$ Recurrence of tumor after a long disease free period has been noted as cancer dormancy. Dormancy is thought to be a period of growth restriction in CTCs. A study by Meng et al. found that $36 \%$ of patients in dormancy had CTCs without clinical evidence of disease. ${ }^{[15]}$ They also found that CTC concentration remained steady in the subsequent blood tests 
among these patients. CTCs have a very short half-life, which implies there must be a replicating population of tumor cells at secondary sites that replenish CTCs and keep them at low levels for many years. There are many hypotheses to explain dormancy: A small number of micrometastases, aging cells, immune surveillance, lack of angiogenic switch, interaction with the microenvironment causing cell cycle arrest. ${ }^{[16]}$

A large portion of tumor cells in bone marrow microenvironment have characteristics associated with stem cells, like the phenotype (aldehyde dehydrogenase 1, claudin low etc.,), resistance to chemotherapy and ability to differentiate into more mature cells. ${ }^{[17]}$ There is accumulating evidence that the origin of cancer stem cells (CSCs) is linked to the EMT program. ${ }^{[18]}$ In a study by Mani et al. to determine if EMT induced cells acquired stem cell traits, they found that most of the resulting cells with mesenchymal characteristics, acquired CD $44^{\text {high }} / \mathrm{CD} 24^{\text {low }}$ expression pattern, which is the phenotype ascribed to breast cancer stem cells (BCSCs). These cells are regulated by both intrinsic and extrinsic signals from the microenvironment. ${ }^{[19]}$ Cytokines produced by endothelial cells and the HER2 gene are important regulators of CSCs. Tumor associated fibroblasts and macrophages and mesenchymal stem cells secrete interleukin 6 (IL6), IL8 and CXCL7, which in turn activates signal transducer and activator of transcription 3/nuclear factor-kappa B leading to self-renewal of BCSCs. ${ }^{[20]}$ They have been shown to possess high levels of adenosine triphosphate binding cassette transporters, which can actively efflux drugs. ${ }^{[21]}$ Furthermore, they are resistant to apoptosis, which can explain dormancy. In a prospective study, it was identified that small numbers of $\mathrm{CD} 44^{+/} \mathrm{CD} 24^{- \text {-low }}$ cells were able to give rise to tumors when passaged into immunocompromised mice. ${ }^{[22]}$ Targeting these CSCs and their molecular survival pathway may decrease the clonogenic potential, survival and reactivation; this in turn, might lead to improved patients' outcome.

\section{CIRCULATING TUMOR CELL DETECTION METHODS}

In 1959, using cytological diagnosis, isolated cancer cells were identified in four cases by Nabar. ${ }^{[23]}$ However, all the cytological methods were found to be low in specificity.

Owing to their rarity, blood needs to be enriched for detection, which can be carried out physically or biologically. Affinity methods based on the antigen expression, is the most commonly used strategy. Certain phenotypic characteristics have been used consistently to detect CTCs in peripheral blood. Positive selection of tumor cells with antibodies against epithelial cell adhesion molecule (EpCAM) is well developed. Subsequent immunocytochemistry detection is usually based on antibodies against CKs, broadly expressed by epithelial tumor cells and absent in hematopoietic cells.

The Cellsearch system is the first automated and Food and Drug Administration approved system for clinical use. ${ }^{[24]}$ One major limitation of this method is considered to be the use of EpCAM expression as theoretically this is downregulated during EMT. Also all EpCAM expressing cells do not express CKs. Recent studies show that CTC markers may change over the course of therapy particularly with the use of biological therapy. Gain of mesenchymal markers such as vimentin and fibronectin was found to correlate with a worse prognosis than CKs. ${ }^{[25]}$

The major step stone in CTC detection using cell search system was the study published by Cristofanilli et al., which identified CTC as a significant predictor of progression free survival (PFS) and overall survival (OS) in MBC patients. ${ }^{[26]}$ This was the first study to use a threshold level of five CTCs per $7.5 \mathrm{ml}$ of blood to distinguish patients with an unfavorable prognosis from patients with favorable prognosis. Regardless of tumor histology, hormone receptor status, and HER2 status, CTC $<5 / 7.5 \mathrm{ml}$ of blood predicted superior PFS and OS. The variation in its level following treatment has also been shown. However, no correlation was found between CTC detection and primary tumor response to neoadjuvant therapy. ${ }^{[27]}$

Another emerging technology within the past decade is the microfluidic platform. Also known as the CTC chip, it can handle very low blood volumes. ${ }^{[28]}$ It consists of an array of microposts coated with EpCAM antibodies. The efficiency of cell capture is directly related to the duration of contact between the CTC and the micropost. Another new device from the same group is the Herring bone chip, which provides an enhanced platform.

Detection of viable CTCs/DTCs has been made possible by the EPISPOT assay. ${ }^{[29]}$ Without direct contact with the target cells, CTCs are assessed based on the secreted or released proteins on a $48 \mathrm{~h}$ short-term culture. There is evidence for the release of full length CK 19 by viable tumor cells, which has been linked to the occurrence or progression of metastasis in breast cancer patients. ${ }^{[30]}$

There is a broad range of target genes used in messenger ribonucleic acid (mRNA) based assays to identify CTCs. Quantitative real time polymerase chain reaction (PCR) has improved detection of CTCs by allowing cut off values of marker transcript numbers where tumor cells deviate from normal cells. ${ }^{[31]}$ Keratin 19 (KRT 19) is most commonly used target gene. The other available markers include mucin 1, mammoglobin, epidermal growth factor receptor (EGFR), 
and KRT 20, which are also expressed at low levels in normal blood and bone marrow cells. The AdnaTest breast cancer select/detect uses reverse transcription-PCR to identify putative transcripts from EpCAM positive cells, isolated by immunomagnetic separation. ${ }^{[32]}$ In a comparison study between AdnaTest and cell search, the concordance rate was found to be $73 \%$. ${ }^{[33]}$ However, there was variation in the positively reported cases by the two methods. In the DETECT study, it was shown that the CTC positivity assessed by Adna Test had no association with clinical outcome parameters such as PFS or OS. ${ }^{[34]}$

In a study to identify microRNAs capable of discriminating CTC positive/negative MBC cases, it was found that miR200 family is an excellent indicator of the CTC status and also the prognosis. ${ }^{[35]}$ Circulating DNA fragments carrying tumor specific sequence alterations are found in cell free fraction of blood. ${ }^{[36]}$ These are released from the apoptotic cells. Analysis of loss of heterozygosity in circulating DNA may provide additional information and combination of such studies could improve the assessment of cancer stage and prognosis. Dawson et al. found a superior sensitivity of circulating tumor DNA (97\%) when compared to CTCs (67\%). ${ }^{[37,38]}$

\section{METASTATIC BREAST CANCER}

In metastatic disease, treatment is usually palliative; so treatment has to be judiciously planned to delay progression and induce clinical improvements, which in turn usually results in the alleviation of symptoms. In a study by Müller et al., CTCs were detected in $39.7 \%$ of patients with metastatic disease at first blood examination. ${ }^{[39]}$ They analyzed blood samples from 47 randomly selected patients before and during systemic therapy. Only nine patients out of 47 had CTCs. But, none of these CTCs turned positive for proliferation associated Ki 67 antigen. This reinforces the heterogeneity of CTC population.

The prognostic power of these CTCs was established in many studies. Hayes et al. published follow-up data on the 177 patients from Cristofanilli study. ${ }^{[40]}$ In this prospective longitudinal study, CTCs were assessed at specified intervals after the start of treatment. Patients with elevated CTCs (>5 CTC per $7.5 \mathrm{ml}$ of blood) at any time point during the treatment had a rapid progression of disease (PFS: 1.3-3.6 months) and an early death (OS: 6.3-10.9 months). Patients who had $>5$ CTCs at baseline, but eventually dropped to <5 CTCs after therapy had the same risk of death as patients who never had elevated CTCs (median OS: 19.8 months). CTCs were found to be low in patients under remission. But, patients were receiving different treatments.
In breast cancer, the commonly used serum markers are carcinoembryonic antigen (CEA), CA27.29 and CA15-3. These are cell surface glycoproteins. ${ }^{[41]}$ Study reported retrieval of $75 \%$ of patients with metastatic relapse by assessing CEA and CA 15-3. Addition of CTC increases detection rate to $90 \%$. There was no clear superiority of CTC over other serum markers. Cristofanilli et al. showed that CTCs are not just a reflection of tumor burden, but cells with unique properties. ${ }^{[42]}$ Their detection was independent of disease phenotype or line of treatment. In a multicenter study correlation was found between radiographic response and CTC variation after starting treatment. ${ }^{[43]}$ But, imaging is not done as early as 3-4 weeks after initiation. Hence CTC assessment was found more feasible than imaging for monitoring treatment efficacy.

The clinical impact of CTCs in various immunohistochemical subtypes of breast cancer, was shown in a study by Giordano. ${ }^{[4]}$ They found that baseline CTC enumeration had good prognostic value in all breast cancer subtypes except HER2 + cancer. In a study by Giuliano et al. the effect of different first line systemic treatment on the prognostic impact of CTCs were studied. ${ }^{[45]}$ They had four different treatment groups-endocrine therapy, chemotherapy alone, chemotherapy plus bevacizumab (angiogenesis inhibitor) and chemotherapy plus HER2 targeting drugs. In both the groups with endocrine treatment and chemotherapy alone, high CTC was associated with a worse prognosis. On the other hand, patients in other two groups receiving either HER2 targeted treatment or biological agent did not maintain the negative prognostic value of high CTCs at the baseline, suggesting a therapeutic benefit from these agents.

High dose chemotherapy with hematological support is used to treat high-grade tumors. Immunocytologic and culture based detection methods revealed 10-16\% tumor cell contamination in the peripheral blood stem cell (PBSC) hematopoietic support. ${ }^{[46-48]}$ In a subsequent study to compare the incidence and quantity of contamination between PBSC and bone marrow, it was found that PBSC tumor involvement $(22.5 \%)$ is less likely than bone marrow tumor cell involvement (70\%). ${ }^{[49]}$ Progenitor cells are mobilized from bone marrow by administering colony-stimulating factors. Are tumor cells also mobilized along with stem cells? In a subsequent study by Ross to compare the contamination between mobilized and nonmobilized grafts, there was no significant difference. ${ }^{[50]}$ Glück et al. in their study found that the contamination dropped significantly after one cycle of induction chemotherapy but further cycles may not be beneficial. ${ }^{[51]}$ The clinical significance of reinfused tumor cells is discussed controversially. ${ }^{[52-54]}$ Most purging methods commonly employed deplete the graft of lymphocytes, which might increase the risk of recurrence. ${ }^{[55]}$ 
Tumor cells were found in the marrow in 30-60\% of patients with metastatic disease, compared with only $1-2 \%$ in patients with primary disease. Several analyses have demonstrated that DTCs in Bone marrow at the time of initial diagnosis of breast cancer is a significant and independent prognostic factor of $O S$ and breast cancer specific survival. Identification of micrometastasis at the initial presentation of breast cancer or after completion of adjuvant treatment could determine, which patient needs additional therapy. ${ }^{[5]}$ In another study by Braun and Pantel, applying broad-spectrum anti-CK antibody A45-B/B3 for tumor cell detection, they found association of bone marrow micrometastasis with diagnosis of inflammatory breast cancer, distant metastasis and lymph node metastasis. ${ }^{[57]}$ Most of these cells lack Ki67 positivity and seem to be resting $G_{0}$ phase. Hence they are likely to resist cytotoxic chemotherapy.

In a recent study to find the comparison between CTCs in peripheral blood and DTCs in bone marrow, it was found that the concordance rate increases from $69.4 \%$ in the primary situation to $75.6 \%$ during follow-up and $78.6 \%$ in metastatic disease. ${ }^{[58]}$ Positivity for DTC was $23.1 \%$ at primary diagnosis, $31.7 \%$ during follow-up and $71 \%$ in metastatic situation. Correspondingly, CTC detection was $14.3 \%, 22 \%$ and $78.6 \%$ respectively. Bone marrow seems to be a stable homing site during cancer dormancy.

\section{EARLY STAGE BREAST CANCER}

In a nonmetastatic setting, the main treatment goals are complete eradication of the disease with reduction or prevention of recurrences. Neoadjuvant therapy, a concept where systemic treatment is given prior to definite surgery, is increasingly used in patients especially with larger tumors and clinically detectable lymph node involvement. No correlation between hematogeneous dissemination and lymphatic spread has been identified so far. ${ }^{\left[{ }^{[9]}\right.}$ In one of the early studies to investigate micrometastasis in primary breast cancer patients, they found marrow involvement in $24 \%$ of node negative patients. ${ }^{[60]}$ This percentage correlated with number of lymph node negative patients who relapsed within 5 years of presentation.

In a study by Lucci et al. to study the prognostic value of CTCs in early stage breast cancer, 73 patients had one or more CTCs, 29 patients had 2 or more CTCs and 16 patients had 3 or more CTCs per $7.5 \mathrm{ml}$ of blood. ${ }^{[61]}$ There was no correlation between primary tumor characteristics and detection of CTCs. Presence of CTC was associated with significantly shorter PFS. Hazard ratio increased with higher numbers of CTCs.
Krishnamurthy et al. conducted a study to evaluate the occurrence of DTCs in bone marrow and CTCs in peripheral blood and to find the correlation between their detection and the standard prognostic factors like tumor size, tumor histologic grade, ER status, progesterone receptor status, HER2 status and axillary lymph node status. ${ }^{[62]}$ CTCs were present in 13 of 43 patients with T1 tumor and in 12 of 38 patients with T2 tumors. CTCs occurred in one of four patients with HER2 positive tumors and in 24 of 77 patients with HER2 negative tumors. CTCs occurred in 10 of 35 patients with lymph node positive disease compared with 15 of 46 patients with lymph node negative disease. There was no correlation between occurrence of CTCs and the standard prognostic factors. They suggested the possibility of independent modes of dissemination to different homing sites. The detection of CTCs and DTCs in lymph node negative early stage tumor questions the role of lymph node status in selecting patients for adjuvant chemotherapy.

In another study by Rack et al., 1767 patients with lymph node negative and node positive early breast cancer were evaluated for the presence of CTCs before and after treatment. ${ }^{[63]} 10 \%$ of patients had $>1$ CTC before treatment, while $7 \%$ patients had $>1$ CTC after treatment. They found a significant correlation between presence of CTCs and lymph node positivity. Another study also reported correlation between CTC, bone marrow micro metastasis and primary tumor characteristics. A total of 38\% (35/92) were CTC positive. Among these patients, 15 received neoadjuvant chemotherapy. ${ }^{[64]}$ The authors found a positive correlation between HER2 status of primary tumor and detection of CTC.

The different molecular subtypes based on the receptors expressed by the primary tumor vary in their response to treatment and have independent clinical outcomes. Ignatiadis et al. in their study found that presence of CK 19 mRNA-positive CTCs predicted worse clinical outcome in the ER negative, triple negative and HER2 positive subgroups of patients. ${ }^{[65]}$ The potential of CTCs to predict relapse and OS in early breast cancer patients may depend on timing of sampling, duration of follow-up and more importantly on the method of CTC detection. The detection of CTCs after adjuvant treatment is an independent adverse prognostic factor.

Amplification of the encoding gene c-erbB2 occurs in about $20-30 \%$ of early breast cancers. ${ }^{[66,67]}$ HER2 positive CTCs are found to play a significant role in metastasis that one-time assessment may not be sufficient. ${ }^{[68]}$ Several reports suggest that HER2 gene amplification may be acquired during progression of disease. In another study conducted 
by Georgoulias in women with early stage breast cancer and HER 2 negative tumor, 51 (89\%) of the 57 analyzed patients had HER2 expressing CTCs. ${ }^{[69]}$ Trastuzumab is the first approved anti-HER2 agent used both in MBC as well as in early breast cancer, if HER2 positive. In a study by Pachmann et al., the benefit from 1 year of trastuzumab therapy in MBC lasted on average only for first 3 years. ${ }^{[70-72]}$ CTC monitoring during trastuzumab treatment might point out patients who will do well. Now studies have shown that dual HER2 blockade by combining two or three agents with nonoverlapping mechanisms of action, improves cell death and tumor shrinkage in HER2 positive tumors. ${ }^{[73,74]}$

\section{FUTURE DIRECTIONS}

Nadal et al. analyzed five biomarkers in CTCs in non-MBC patients. ${ }^{[75]}$ No correlation was found between EGFR, HER2 or topoisomerase $2 \mathrm{~A}$ status of CTC and clinico-pathological characteristics. Anti-EGFR therapy can act over the entire HER-2 pathway downstream. The phosphatidylinositol 3 kinase pathway activated by transmembrane receptor tyrosine kinases' including epidermal growth factor family is encoded by PIK3CA gene. ${ }^{[76]}$ In a recent study, laser capture microdissection analysis of some cases showed discrepancy in mutation of this gene within the tumor. Also, discrepancy was found between primary tumor and metastasis with a tendency towards gain of mutations in metastasis. CTC analysis in this direction may add to our knowledge about targeted therapy. Mammoglobin A is another specific molecular marker associated with poor disease free survival. ${ }^{[77]}$

Chimonidou et al. conducted a study to look for the status of tumor suppressor genes and metastasis suppressor gene on the CTCs. ${ }^{[78]}$ They extracted the DNA from EpCAM positive cells. Using methylation specific PCR, the promoter sequences of cystin (CST6), breast cancer metastasis suppressor 1 (BRMS1) and SOX17 were analyzed. Methylation of these cancer related genes is an important biomarker for early detection and prognosis estimation. Cystin M (CST6) is an endogenous inhibitor of cathepsins L and B, which are downregulated in MBC. DNA hypermethylation in its locus impairs transcription. BRMS1 regulates multiple other genes leading to suppression of EGFR and downstream Akt signaling. SRY-Box 17 (sex determining region $\mathrm{Y}$ ) regulates development and precursor cell function at least partly through repression of $\mathrm{Wnt} / \beta$-catenin signaling pathway. Promoter region DNA hypermethylation, as in the earlier case, results in epigenetic silencing. CST6 promoter methylation in CTCs was observed in 10/56 patients with operable breast cancer and 10/27 patients with verified metastasis. Similarly BRMS1 and SOX17 promoter regions were highly methylated in CTCs.
A Powell et al. in their study divided CTCs into two major clusters based on their gene expression data. ${ }^{[79]}$ Both the clusters shared some metastatic genes like the EMT associated genes. There was a high transcript level of PTEN gene in $83 \%$ of CTCs, which is inversely associated with TGF-beta expression. TGF-beta is an important regulator of breast development and its pathway is considered crucial in metastasis. Also, their data showed absence of cell adhesion protein CDH1 in CTCs.

Circulating tumor cell molecular profiling identifies diverse phenotypes, which require optimized treatment regimens to target all the subtypes of CTCs. Once the functional response of genes with higher level of transcription is identified in relation to clinical outcome, metastasis site and patient characteristics, new drugs can be developed. Recently, there has been a hypothesis about CTC hemodialysis in the postoperative course of breast cancer patients. ${ }^{\left[{ }^{80]}\right.}$ It needs to be validated in terms of curative effect and therapeutic periodicity. Circulating levels of extracellular domain of HER2 receptor can be monitored to detect recurrence and also to predict response. ${ }^{[81]}$

\section{SUMMARY}

Circulating tumor cell in MBC can be used as a tumor marker and to guide therapy decisions, more definite prospective studies are awaited. These will increase the predictive power of CTCs for therapy decisions. In early breast cancer, data are still immature for clinical use and need more validation studies. By the use of molecular markers on the CTCs themselves, it can become a powerful tool as predictive marker for therapy and also help decide upon which biological agents to use.

\section{REFERENCES}

I. Johnson RH, Chien FL, Bleyer A. Incidence of breast cancer with distant involvement among women in the United States, 1976 to 2009. JAMA 2013;309:800-5.

2. Klein CA. Parallel progression of primary tumours and metastases. Nat Rev Cancer 2009;9:302-12.

3. Swaby RF, Cristofanilli M. Circulating tumor cells in breast cancer: A tool whose time has come of age. BMC Med 2011;9:43.

4. Balic M, Williams A, Lin H, Datar R, Cote RJ. Circulating tumor cells: From bench to bedside. Annu Rev Med 2012;64:31-44.

5. Mego M, Mani SA, Cristofanilli M. Molecular mechanisms of metastasis in breast cancer - clinical applications. Nat Rev Clin Oncol 2010;7:693-70I.

6. Yu M, Bardia A, Wittner BS, Stott SL, Smas ME, Ting DT, et al. Circulating breast tumor cells exhibit dynamic changes in epithelial and mesenchymal composition. Science 2013;339:580-4.

7. Bastid J. EMT in carcinoma progression and dissemination: Facts, unanswered questions, and clinical considerations. Cancer Metastasis Rev 2012;31:277-83.

8. Bednarz-Knoll N, Alix-Panabières C, Pantel K. Plasticity of disseminating cancer cells in patients with epithelial malignancies. Cancer Metastasis Rev 2012;31:673-87.

9. Langley RR, Fidler IJ. The seed and soil hypothesis revisited - The role of 
tumor-stroma interactions in metastasis to different organs. Int J Cancer 20I I; I 28:2527-35.

10. Joyce JA, Pollard JW. Microenvironmental regulation of metastasis. Nat Rev Cancer 2009;9:239-52.

II. Guise T. Examining the metastatic niche: Targeting the microenvironment. Semin Oncol 2010;37 Suppl 2:S2-I4.

12. Joosse SA, Hannemann J, Spötter J, Bauche A, Andreas A, Müller V, et al. Changes in keratin expression during metastatic progression of breast cancer: Impact on the detection of circulating tumor cells. Clin Cancer Res 2012;18:993-1003.

13. Bettelheim R, Penman HG, Thornton-Jones H, Neville AM. Prognostic significance of peritumoral vascular invasion in breast cancer. $\mathrm{Br}$ J Cancer 1984;50:77I-7.

14. Uhr JW, Pantel K. Controversies in clinical cancer dormancy. Proc Natl Acad Sci U SA 201 I; 108:12396-400.

I5. Meng S, Tripathy D, Frenkel EP, Shete S, Naftalis EZ, Huth JF, et al. Circulating tumor cells in patients with breast cancer dormancy. Clin Cancer Res 2004;10:8152-62.

16. Willis L, Alarcón T, Elia G, Jones JL, Wright NA, Tomlinson IP, et al. Breast cancer dormancy can be maintained by small numbers of micrometastases. Cancer Res 2010;70:4310-7.

I7. Patel P, Chen El. Cancer stem cells, tumor dormancy, and metastasis. Front Endocrinol (Lausanne) 20I2;3:I25.

18. Mani SA, Guo W, Liao MJ, Eaton EN, Ayyanan A, Zhou AY, et al. The epithelial-mesenchymal transition generates cells with properties of stem cells. Cell 2008; I33:704-I5.

19. May CD, Sphyris N, Evans KW, Werden SJ, Guo W, Mani SA. Epithelial-mesenchymal transition and cancer stem cells: A dangerously dynamic duo in breast cancer progression. Breast Cancer Res 201 I; 13:202.

20. Korkaya H, Liu S, Wicha MS. Breast cancer stem cells, cytokine networks, and the tumor microenvironment. J Clin Invest 201 1;121:3804-9.

21. Korkaya H,Wicha MS. Breast cancer stem cells:We've got them surrounded. Clin Cancer Res 2013;19:5II-3.

22. Aktas B, Tewes M, Fehm T, Hauch S, Kimmig R, Kasimir-Bauer S. Stem cell and epithelial-mesenchymal transition markers are frequently overexpressed in circulating tumor cells of metastatic breast cancer patients. Breast Cancer Res 2009; I I:R46.

23. NABAR BV.A study in isolating circulating cancer cells from blood. J Clin Pathol 1962;15:380-2.

24. Pantel K, Alix-Panabières C, Riethdorf S. Cancer micrometastases. Nat Rev Clin Oncol 2009;6:339-5I.

25. Joosse SA, Pantel K. Biologic challenges in the detection of circulating tumor cells. Cancer Res 2013;73:8-II.

26. Cristofanilli M, Budd GT, Ellis MJ, Stopeck A, Matera J, Miller MC, et al. Circulating tumor cells, disease progression, and survival in metastatic breast cancer. N Engl J Med 2004;35I:78I-9I.

27. Cristofanilli M, Hayes DF, Budd GT, Ellis MJ, Stopeck A, Reuben JM, et al. Circulating tumor cells: A novel prognostic factor for newly diagnosed metastatic breast cancer. J Clin Oncol 2005;23:1420-30.

28. Balic M, Lin H,Williams A, Datar RH, Cote RJ. Progress in circulating tumor cell capture and analysis: Implications for cancer management. Expert Rev Mol Diagn 2012;12:303-12.

29. Alix-Panabières $C$, Pantel K. Circulating tumor cells: Liquid biopsy of cancer. Clin Chem 2013;59:1 10-8.

30. Alix-Panabières C,Vendrell JP, Slijper M, Pellé O, Barbotte E, Mercier G, et al. Full-length cytokeratin-19 is released by human tumor cells:A potential role in metastatic progression of breast cancer. Breast Cancer Res 2009; I :R39.

31. Lianidou ES, Markou A. Circulating tumor cells in breast cancer: Detection systems, molecular characterization, and future challenges. Clin Chem 20I I;57: I242-55.

32. Pantel K, Brakenhoff RH, Brandt B. Detection, clinical relevance and specific biological properties of disseminating tumour cells. Nat Rev Cancer 2008;8:329-40.

33. Andreopoulou E, Yang LY, Rangel KM, Reuben JM, Hsu L, Krishnamurthy S, et al. Comparison of assay methods for detection of circulating tumor cells in metastatic breast cancer:AdnaGen AdnaTest BreastCancer Select/Detect ${ }^{\text {TM }}$ versus Veridex CellSearch ${ }^{\mathrm{TM}}$ system. Int J Cancer 2012;130:1590-7.

34. Müller V, Riethdorf S, Rack B, Janni W, Fasching PA, Solomayer E, et al. Prognostic impact of circulating tumor cells assessed with the CellSearch
System $^{\mathrm{TM}}$ and AdnaTest Breast ${ }^{\mathrm{TM}}$ in metastatic breast cancer patients: The DETECT study. Breast Cancer Res 20I2; I4:RII8.

35. Madhavan D, Zucknick M, Wallwiener M, Cuk K, Modugno C, Scharpff M, et al. Circulating miRNAs as surrogate markers for circulating tumor cells and prognostic markers in metastatic breast cancer. Clin Cancer Res 20I2; 18:5972-82.

36. Lippman M, Osborne CK. Circulating tumor DNA - Ready for prime time? N Engl J Med 2013;368: I249-50.

37. Dawson SJ, Rosenfeld N, Caldas C. Circulating tumor DNA to monitor metastatic breast cancer. N Engl J Med 2013;369:93-4.

38. Alix-Panabières $\mathrm{C}$, Schwarzenbach $\mathrm{H}$, Pantel $\mathrm{K}$. Circulating tumor cells and circulating tumor DNA.Annu Rev Med 2012;63:199-2I5.

39. Müller V, Stahmann N, Riethdorf S, Rau T, Zabel T, Goetz A, et al. Circulating tumor cells in breast cancer: Correlation to bone marrow micrometastases, heterogeneous response to systemic therapy and low proliferative activity. Clin Cancer Res 2005; I 1:3678-85.

40. Hayes DF, Cristofanilli M, Budd GT, Ellis MJ, Stopeck A, Miller MC, et al. Circulating tumor cells at each follow-up time point during therapy of metastatic breast cancer patients predict progression-free and overall survival. Clin Cancer Res 2006; 12:4218-24.

4I. Bidard FC, Hajage D, Bachelot T, Delaloge S, Brain E, Campone M, et al. Assessment of circulating tumor cells and serum markers for progression-free survival prediction in metastatic breast cancer: A prospective observational study. Breast Cancer Res 20I2; I4:R29.

42. Cristofanilli M, Broglio KR, Guarneri V, Jackson S, Fritsche HA, Islam R, et al. Circulating tumor cells in metastatic breast cancer: Biologic staging beyond tumor burden. Clin Breast Cancer 2007;7:47I-9.

43. Budd GT, Cristofanilli M, Ellis MJ, Stopeck A, Borden E, Miller MC, et al. Circulating tumor cells versus imaging - Predicting overall survival in metastatic breast cancer. Clin Cancer Res 2006; 12:6403-9.

44. Giordano A, Giuliano M, De Laurentiis M, Arpino G, Jackson S, Handy BC, et al. Circulating tumor cells in immunohistochemical subtypes of metastatic breast cancer: Lack of prediction in HER2-positive disease treated with targeted therapy. Ann Oncol 20 I 2;23: I I44-50.

45. Giuliano M, Giordano A, Jackson S, Hess KR, De Giorgi U, Mego M, et al. Circulating tumor cells as prognostic and predictive markers in metastatic breast cancer patients receiving first-line systemic treatment. Breast Cancer Res 20II;I3:R67.

46. Brugger W, Bross KJ, Glatt M,Weber F, Mertelsmann R, Kanz L. Mobilization of tumor cells and hematopoietic progenitor cells into peripheral blood of patients with solid tumors. Blood 1994;83:636-40.

47. Moss TJ, Ross AA. The risk of tumor cell contamination in peripheral blood stem cell collections. J Hematother 1992; I:225-32.

48. Crump M, Gluck S, Tu D, Stewart D, Levine M, Kirkbride P, et al. Randomized trial of high-dose chemotherapy with autologous peripheral-blood stem-cell support compared with standard-dose chemotherapy in women with metastatic breast cancer: NCIC MA. 16. J Clin Oncol 2008;26:37-43.

49. Ross AA, Cooper BW, Lazarus HM, Mackay W, Moss TJ, Ciobanu N, et al. Detection and viability of tumor cells in peripheral blood stem cell collections from breast cancer patients using immunocytochemical and clonogenic assay techniques. Blood 1993;82:2605-10.

50. Ross AA, Layton TJ, Ostrander AB, Passos-Coelho JL, Davis JM, Huelskamp AM, et al. Comparative analysis of breast cancer contamination in mobilized and nonmobilized hematopoietic grafts. J Hematother 1996;5:549-52.

5I. Glück S, Ross AA, Layton TJ, Ostrander AB, Goldstein LC, Porter K, et al. Decrease in tumor cell contamination and progenitor cell yield in leukapheresis products after consecutive cycles of chemotherapy for breast cancer treatment. Biol Blood Marrow Transplant 1997;3:3 I 6-23.

52. Cooper BW, Moss TJ, Ross AA, Ybanez J, Lazarus HM. Occult tumor contamination of hematopoietic stem-cell products does not affect clinical outcome of autologous transplantation in patients with metastatic breast cancer. J Clin Oncol 1998;16:3509-17.

53. Syme R, Stewart D, Rodriguez-Galvez M, Luider J, Auer Y, Klassen J, et al. Micrometastases in apheresis products predict shorter progression-free and overall survival in patients with breast cancer undergoing high-dose chemotherapy (HDCT) and autologous blood stem cell transplantation (ABSCT). Bone Marrow Transplant 2003;32:307-I I.

54. Müller AM, Kohrt HE, Cha S, Laport G, Klein J, Guardino AE, et al. Long-term 
outcome of patients with metastatic breast cancer treated with high-dose chemotherapy and transplantation of purified autologous hematopoietic stem cells. Biol Blood Marrow Transplant 20।2; | 8: 125-33.

55. Nieto Y, Shpall EJ. High-dose chemotherapy with autologous stem cell transplant for breast cancer: What have we learned 25 years later? Biol Blood Marrow Transplant 2012; 18:3-5.

56. Braun S, Vogl FD, Naume B, Janni W, Osborne MP, Coombes RC, et al. A pooled analysis of bone marrow micrometastasis in breast cancer. $\mathrm{N}$ Engl J Med 2005;353:793-802.

57. Braun S, Pantel K. Micrometastatic bone marrow involvement: Detection and prognostic significance. Med Oncol 1999; I6:154-65.

58. Schindlbeck C, Andergassen U, Hofmann S, Jückstock J, Jeschke U, Sommer $\mathrm{H}$, et al. Comparison of circulating tumor cells (CTC) in peripheral blood and disseminated tumor cells in the bone marrow (DTC-BM) of breast cancer patients. J Cancer Res Clin Oncol 2013;139:1055-62.

59. Pantel K, Brakenhoff RH. Dissecting the metastatic cascade. Nat Rev Cancer 2004;4:448-56.

60. Redding WH, Coombes RC, Monaghan P, Clink HM, Imrie SF, Dearnaley DP, et al. Detection of micrometastases in patients with primary breast cancer. Lancet 1983;2:127|-4.

6I. Lucci A, Hall CS, Lodhi AK, Bhattacharyya A, Anderson AE, Xiao L, et al. Circulating tumour cells in non-metastatic breast cancer: A prospective study. Lancet Oncol 2012; 13:688-95.

62. Krishnamurthy S, Cristofanilli M, Singh B, Reuben J, Gao H, Cohen EN, et al. Detection of minimal residual disease in blood and bone marrow in early stage breast cancer. Cancer 2010;1 16:3330-7.

63. Rack BK, Schindlbeck C, Hofmann S, Schneeweiss A, Rezai M, Beckmann MW, et al. Circulating tumor cells in peripheral blood of primary breast cancer patients. J Clin Oncol 2007;25:No I8_Suppl: 10595.

64. Lang JE, Mosalpuria K, Cristofanilli M, Krishnamurthy S, Reuben J, Singh B, et al. HER2 status predicts the presence of circulating tumor cells in patients with operable breast cancer. Breast Cancer Res Treat 2009; I 1 3:50 I-7.

65. Ignatiadis M, Xenidis N, Perraki M, Apostolaki S, Politaki E, Kafousi M, et al. Different prognostic value of cytokeratin-19 mRNA positive circulating tumor cells according to estrogen receptor and HER2 status in early-stage breast cancer. J Clin Oncol 2007;25:5194-202.

66. Bewick M, Chadderton T, Conlon M, Lafrenie R, Morris D, Stewart D, et al. Expression of C-erbB-2/HER2 in patients with metastatic breast cancer undergoing high-dose chemotherapy and autologous blood stem cell support. Bone Marrow Transplant 1999;24:377-84.

67. Wülfing P, Borchard J, Buerger H, Heidl S, Zänker KS, Kiesel L, et al. HER2-positive circulating tumor cells indicate poor clinical outcome in stage I to III breast cancer patients. Clin Cancer Res 2006; I2: I I I5-20.

68. Meng S, Tripathy D, Shete S, Ashfaq R, Haley B, Perkins S, et al. HER2 gene amplification can be acquired as breast cancer progresses. Proc Natl Acad Sci U SA 2004; 101:9393-8.

69. Georgoulias V, Bozionelou V, Agelaki S, Perraki M, Apostolaki S, Kallergi G, et al. Trastuzumab decreases the incidence of clinical relapses in patients with early breast cancer presenting chemotherapy-resistant
CK-19mRNA-positive circulating tumor cells: Results of a randomized phase II study. Ann Oncol 20I2;23:I744-50.

70. Romond EH, Perez EA, Bryant J, Suman VJ, Geyer CE Jr, Davidson NE, et al. Trastuzumab plus adjuvant chemotherapy for operable HER2-positive breast cancer. N Engl J Med 2005;353:1673-84.

71. Buzdar AU, Ibrahim NK, Francis D, Booser DJ, Thomas ES, Theriault RL, et al. Significantly higher pathologic complete remission rate after neoadjuvant therapy with trastuzumab, paclitaxel, and epirubicin chemotherapy: Results of a randomized trial in human epidermal growth factor receptor 2-positive operable breast cancer. J Clin Oncol 2005;23:3676-85.

72. Pachmann K, Camara O, Kroll T, Gajda M, Gellner AK, Wotschadlo J, et al. Efficacy control of therapy using circulating epithelial tumor cells (CETC) as "liquid biopsy": Trastuzumab in HER2/neu-positive breast carcinoma. J Cancer Res Clin Oncol 201 I;137:1317-27.

73. Prat A, Baselga J. Dual human epidermal growth factor receptor 2 (HER2) blockade and hormonal therapy for the treatment of primary HER2-positive breast cancer: One more step toward chemotherapy-free therapy. J Clin Oncol 2013;31:1703-6.

74. Glück S, Arteaga CL, Osborne CK. Optimizing chemotherapy-free survival for the ER/HER2-positive metastatic breast cancer patient. Clin Cancer Res 20II;| 7:5559-6I.

75. Nadal R, Fernandez A, Sanchez-Rovira P, Salido M, Rodríguez M, García-Puche JL, et al. Biomarkers characterization of circulating tumour cells in breast cancer patients. Breast Cancer Res 20I2; |4:R7I.

76. Dupont Jensen J, Laenkholm AV, Knoop A, Ewertz M, Bandaru R, Liu W, et al. PIK3CA mutations may be discordant between primary and corresponding metastatic disease in breast cancer. Clin Cancer Res 20I I; 17:667-77.

77. Dong $X$, Alpaugh KR, Cristofanilli M. Circulating tumor cells (CTCs) in breast cancer: A diagnostic tool for prognosis and molecular analysis. Chin J Cancer Res 2012;24:388-98.

78. Chimonidou M, Strati A, Tzitzira A, Sotiropoulou G, Malamos N, Georgoulias V, et al. DNA methylation of tumor suppressor and metastasis suppressor genes in circulating tumor cells. Clin Chem 2011;57:1169-77.

79. Powell AA, Talasaz AH, Zhang H, Coram MA, Reddy A, Deng G, et al. Single cell profiling of circulating tumor cells: Transcriptional heterogeneity and diversity from breast cancer cell lines. PLoS One 2012;7:e33788.

80. Wang X, Sun Q, Mao F, Shen S, Huang L. CTCs hemodialysis: Can it be a new therapy for breast cancer? Med Hypotheses 20I3;80:99-I0I.

8I. Carney WP, Neumann R, Lipton A, Leitzel K, Ali S, Price CP. Monitoring the circulating levels of the HER2/neu oncoprotein in breast cancer. Clin Breast Cancer 2004;5:105-16.

How to cite this article: Pukazhendhi G, Glück S. Circulating tumor cells in breast cancer. J Carcinog 2014;13:8.

Source and Support: Nil. Conflict of Interest: None declared.

\section{AUTHOR'S PROFILE}

Dr. Geetha Pukazhendhi: Research Assistant, Sylvester Comprehensive Cancer Center, University of Miami, Miller School of Medicine, Aspirant Internal Medicine Resident

Dr. Stefan Glück: Medical Oncologist, Focus Breast Cancer, Sylvester Distinguished Professor, Department of Medicine Division of Hematology/ Oncology Sylvester Comprehensive Cancer Center University of Miami, Leonard M. Miller School of Medicine

\begin{abstract}
Xo Journal of Carcinogenesis is published for Carcinogenesis Press by Medknow Publications and Media Pvt. Ltd.

Manuscripts submitted to the journal are peer reviewed and published immediately upon acceptance, cited in PubMed and archived on PubMed Central. Your research papers will be available free of charge to the entire biomedical community. Submit your next manuscript to Journal of Carcinogenesis. www.journalonweb.com/jcar/
\end{abstract}

